\title{
The design, development and evaluation of a virtual reality based learning environment
}

\author{
Chwen Jen Chen \\ Universiti Malaysia Sarawak
}

\begin{abstract}
Many researchers and instructional designers increasingly recognise the benefits of utilising three dimensional virtual reality (VR) technology in instruction. In general, there are two types of VR system, the immersive system and the non-immersive system. This article focuses on the latter system that merely uses the conventional personal computer setting. Although VR is recognised as an impressive learning tool, there are still many issues that need further investigations. These include (i) identifying the appropriate theories and/or models to guide its design and development, (ii) investigating how its attributes are able to support learning, finding out whether its use can improve the intended performance and understanding, and investigating ways to reach more effective learning when using this technology, and (iii) investigating its impact on learners with different aptitudes. This project chose a learning problem that was related to novice car driver instruction, to study some aspects of these issues. Indeed, the study provided valuable insights to a feasible instructional design theoretical framework, as well as an instructional development framework for VR based learning environments. In addition, it also developed understanding of the educational effectiveness of such a learning environment and its effect on learners with different aptitude.
\end{abstract}

\section{Introduction}

Three dimensional virtual reality (VR) is one of the latest innovations in the long line of technologies that can be used for teaching and learning. Although VR seems to offer promising instructional benefits, there are still many issues that need further investigation. Gustafson (2002) classifies low cost three dimensional visualisation and "walk around" VR as a few of the technologies that will revolutionise how people of all ages learn and work, and Rieber (1996) assures that this technology has the potential to facilitate the acquisition of higher order thinking and problem solving skills. However, they also believe that much exciting research and development work remains to be done. 
As with any other technological advancement, the introduction of this technology brings about excitement and high expectation among educators of its capabilities. However, it is important to note that this technology is merely a tool, as is a chalkboard, television, overhead projector, or an Internet connection. Tools by themselves do not teach. They have to be carefully and effectively implemented to assist in the learning process. As pointed out by Reigeluth and Frick (1999), more instructional design theories are needed to provide guidance on the use of new information technology tools. Hence, the pertinent questions would be on how to design instruction to enable the effective utilisation of VR capabilities to support the desired outcomes. What are the appropriate theories and/or models to guide the design and development of such learning environments?

Youngblut (1998) who has done a rather comprehensive review of educational uses of VR technology reveals that most educational applications are not thoroughly evaluated in terms of their educational effectiveness. As pointed out by Jonassen, Hernandez-Serrano and Choi (2000), technologies were previously employed for communicating knowledge. However, in recent years, technologies are reconceived as contexts, productivity tools, and thinking tools. In view of the fact that effective learning is the ultimate aim of any teaching and learning efforts and the roles of new technologies in teaching and learning are changing, it is thus crucial to perform educational effectiveness evaluation. Such evaluation, in the case of novice car driver instruction, intends to find out whether the use of a three dimensional VR based learning environment can improve the intended performance and understanding, and to investigate how the attributes of this technology are able to support learning in a way that conventional instructional methods are unable to provide (Kozma, 1994). This is succinctly articulated by Roblyer and Knezek (2003), who suggest that technologies should not be viewed as delivery systems, rather as components of solutions to educational problems.

\section{Purpose}

This project aimed to pursue development goals (Reeves, 2000) by focusing on the dual objectives of developing a plausible solution to solve a learning problem in a real context, while at the same time constructing a feasible instructional design and development framework that could guide future developmental efforts. It started by addressing a learning problem in a real context and, as elaborated earlier, the identified learning problem was related to the novice car driver instruction program in Malaysia. This learning problem focused on the understanding of traffic rules for various road scenarios including ordinary roads, different types of road junctions, and related traffic signs. Then, a plausible solution to this learning problem 
was designed and developed by integrating known and hypothetical design principles with technological affordances. A recursive and reflective approach was employed to evaluate and refine the solution. Finally, an evaluation that employed a quasi-experimental design was conducted to investigate the effects of the developed learning environment on learning, and to investigate the effects of learners' spatial visualisation abilities on learning.

Spatial visualisation is a measure of the ability to mentally restructure or manipulate the components of the visual stimulus and involves recognising, retaining and recalling configurations when the figure or parts of the figure are moved (McGee, 1979). In line with this, VR is known as a promising medium for teaching people about the spatial characteristics of places and situations due to its inherent spatial nature. To date, many studies have been conducted to investigate the interaction of individuals' spatial abilities with the characteristics of VR. Hence, a focus of the evaluation study of this project is to further investigate this issue in an effort to adapt the nature of VR based instruction to accommodate individuals of different spatial abilities.

The following are the specific objectives for this project:

- to analyse a learning problem in a real context, in collaboration with subject matter experts and by reviewing the related materials. The identified learning problem concerned novice car driver instruction in Malaysia, focusing solely on the cognitive aspect.

- to design a solution for the learning problem, which was a VR based learning environment, by aligning the technological affordances with the instructional design theoretical framework.

- to develop the VR based learning environment.

- to conduct a field test, which was a pre-test, post-test quasiexperimental study comparing two learning modes (VR mode utilised the VR based learning environment and Non VR mode utilised the conventional learning methods) to measure the effects of each learning mode on learning.

- to conduct an aptitude by treatment interaction (ATI) study to investigate the effects of learners' spatial visualisation abilities and the possible interaction effects between the two learning modes and this aptitude. 


\section{Methodology}

This section first provides a description of the learning problem. It then describes in detail the methodology for the design, development and evaluation of the VR based learning environment for this learning problem.

\section{Analysis of the learning problem}

As reported in a local newspaper item, Computer based traffic rules and regulations test: More than 200,000 failures (in Chinese, 28 November 2003), from May 2002 until August 2003, about 500,000 candidates undertook the Road Transport Department (RTD) computer based theory test. However, only 219,965 passed the test. Further investigation revealed that those who did not pass the test had difficulty in studying the materials, which is in the form of text and two dimensional static images.

Indeed, the current methods of instruction for the cognitive domain, which rely on textbook and basic practical lessons, are observed to pose various limitations in assisting learners in recalling or recognising knowledge, and developing their understandings, intellectual abilities and skills. These include supporting learners with different cognitive abilities, providing authentic and meaningful tasks, providing concrete experience and active experimentation to support this type of learning style, and providing learner directed learning. On the other hand, the various capabilities of the VR technology are foreseen to be able to overcome the observed problems, such as its ability to provide three dimensional representation, authentic representation, an excellent visualisation tool, multiple perspectives, controlled level of complexity, active learning, learner centred, and strong positive emotional reaction. Chen, Toh and Wan (2003) provide a thorough description of these limitations and highlight the potential of VR to overcome them.

\section{Design, development and evaluation}

The following describes the instructional design theoretical framework and each activity of the instructional development model that was employed in developing the VR based learning environment.

Instructional design theoretical framework

The instructional design theoretical underpinnings provided guidance about the methods for facilitating learning. They provided guidelines on determining the design of the VR based learning environment.

An eclectic approach uses a combination of principles from different theories (Alessi \& Trollip, 2001). This project took such an approach by 
combining the concept of integrative goals, as proposed by Gagné and Merrill (1990), with the model for designing constructivist learning environments, as proposed by Jonassen (1999). They served as the macrostrategy, which according to Reigeluth and Merrill (1978) is concerned with the selection, sequence, and organisation of the subject matter topics that are to be presented. A constructivist paradigm was chosen as it is in accord with the new paradigm of instruction, and more important, VR capabilities are found to be compatible with the constructivist learning principles (Bricken, 1990; Chen \& Teh, 2000; Winn, 1993). Additionally, the cognitive theory of multimedia learning, from which a number of principles for the design of multimedia messages are derived (Mayer, 2002), served as the micro-strategy that basically, is concerned with presentation strategies. Figure 1 depicts the instructional design theoretical framework, and Chen, Toh and Wan (2004) provided the details of how this theoretical framework guides the design of the learning environment.

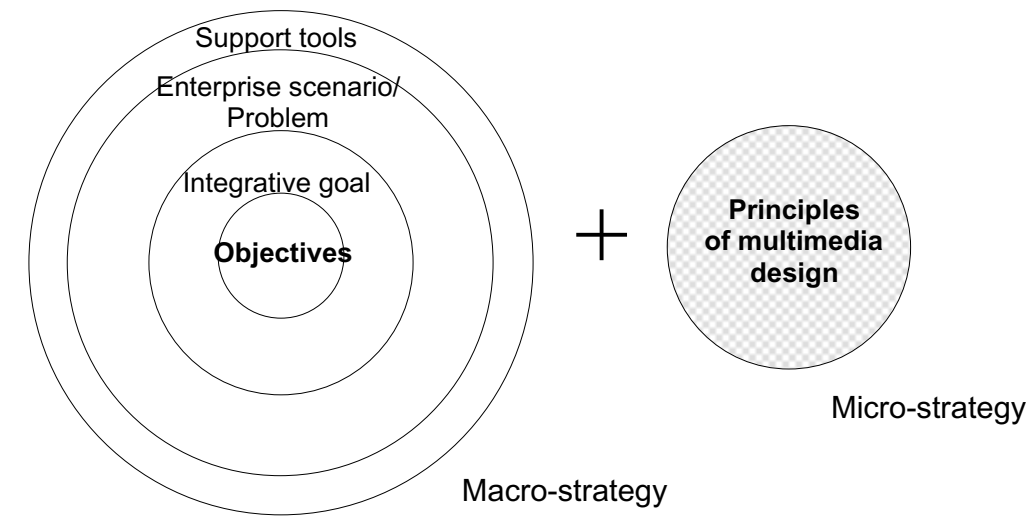

Figure 1: Instructional design theoretical framework of the VR based learning environment

Instructional development model

The instructional development model concerns what process an instructional designer should use to plan and prepare for the instruction (Reigeluth, 1999). The learning environment of this project (Figure 2 shows a screenshot) adopted the Recursive, Reflective Design and Development (R2D2) model. This constructivist instructional development model was put forward by Willis (1995) and later revised in Willis and Wright (2000). Three important but flexible guidelines for R2D2 model include (i) recursive, non-linear design; (ii) reflective design; and (iii) participatory design (Willis, 2000) This model was used to guide the design, development and evaluation of the learning environment. It has three focal 
points: Define, Design and Development, and Dissemination. The details of the work done in the Define focal point and the Design and Development focal point are reported in Chen and Toh (2005). This paper focuses on the Dissemination focal point.

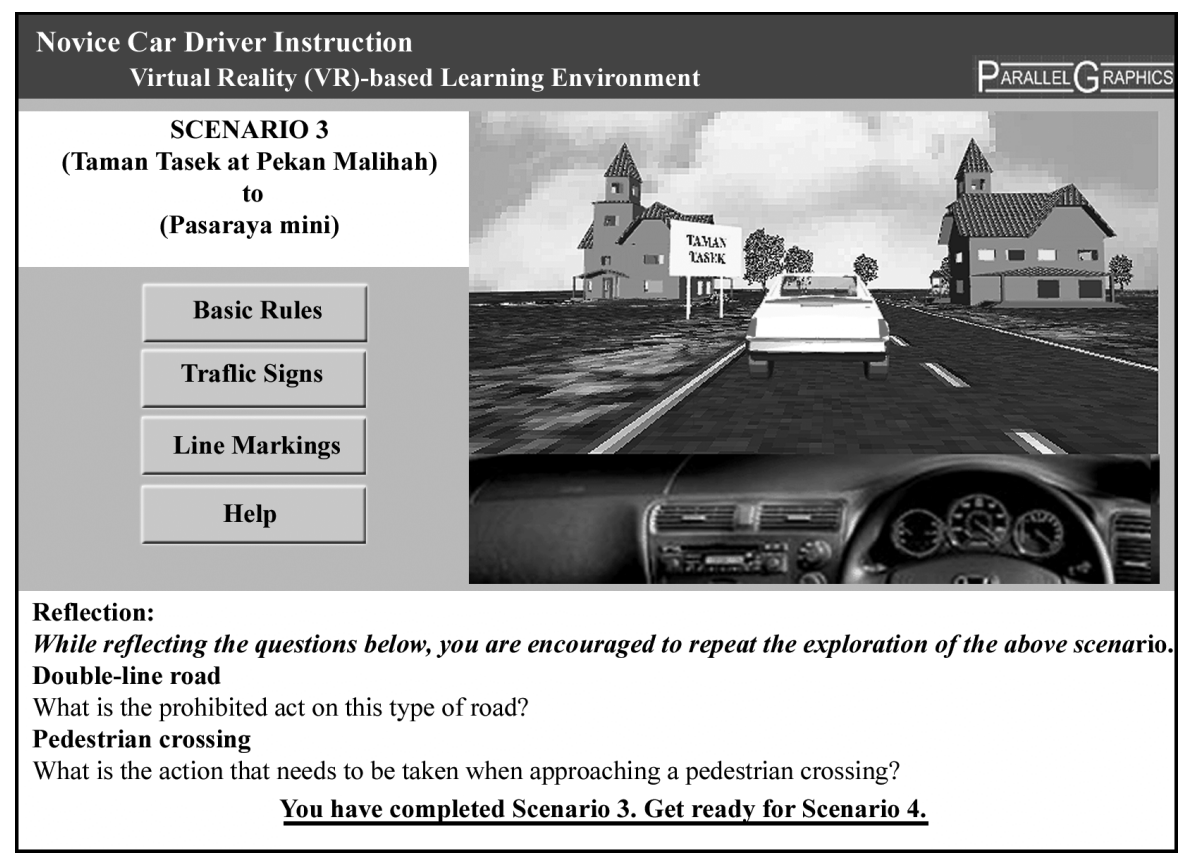

Figure 2: A screenshot of the VR based learning environment depicting the incorporation of problem, cognitive tools and instructional activities

\section{Dissemination focus}

This focal point comprises four activities: summative evaluation, packaging, diffusion, and adoption. However, this project looked into the first activity, which was a summative evaluation to measure the outcomes of each learning mode.

The study employed a pre-test, post-test quasi-experimental design. This design involved two groups, VR and Non VR. Each group was given a pretest and a post-test. However, the groups did not have pre-experimental sampling equivalence. The groups constituted intact classes, in which equivalency could not be presumed or assured. 


\section{Population and sample}

The current law in this country allows any person who is 17 years old and above to undergo the novice car driver instruction program. Although the ages of these candidates may vary greatly, according to Mohd Kifli, the former Head of the Driving License Unit at Penang RTD, the majority are from the younger group, those who are just over the eligible age (personal communication, 25 February 2003). Hence, only individuals from this group of population were chosen to evaluate the VR based learning environment, which also implied that the usability of the learning environment only took into account the cognitive abilities of this group of the population. This majority formed the targeted population of this study.

Due to time and cost constraints, the accessible population for this study encompassed Form Four students only (limited to those who had not undergone the driver instruction program) of any Penang Island secondary schools that were well-equipped with multimedia computer laboratories. Form Four students were chosen because they were a non-examination class and more important, they were within the targeted population as their age was approximately the minimum eligible age to undergo the novice car driver instruction program. School students were chosen instead of the general public, in order to obtain better controlled samples. The sample size was 126 and the average age of the participants was 16.55 years.

Three secondary schools were randomly selected (based on the simple random sampling technique) from the list of daily secondary schools on Penang Island. For each school, three intact classes were randomly chosen. All eligible students (those who had not undergone the driver instruction program) in the selected classes were included in the study. These selected classes were randomly assigned to either VR group or Non VR group.

\section{Material}

The VR based learning environment served as the treatment for the VR group while the Non VR group utilised the conventional learning method that relied on lectures and reading materials.

\section{Instruments}

The instruments that were used include the VR based test (pre-test and post-test) and the Bennett, Seashore and Wesman Space Relations Test.

$V R$ based test (pre-test and post-test)

The VR based pre-test and VR based post-test that were employed in this study were computer based. Each test consisted of 15 questions and aimed 
to assess the learners' understanding of traffic rules and traffic signs. Unlike the conventional theory test, set by RTD, that showed two dimensional images, each of the questions in the VR based test showed a three dimensional simulation of a virtual road scenario and the learners were instructed to identify an observable error within the simulation, if any.

Nyatakan kesalahan lalulintas yang anda dapat kenalpasti (jika ada) dalam simulasi yang ditunjukkan. Tekan 'F5' untuk ulangi demonstrasi, jika perlu.

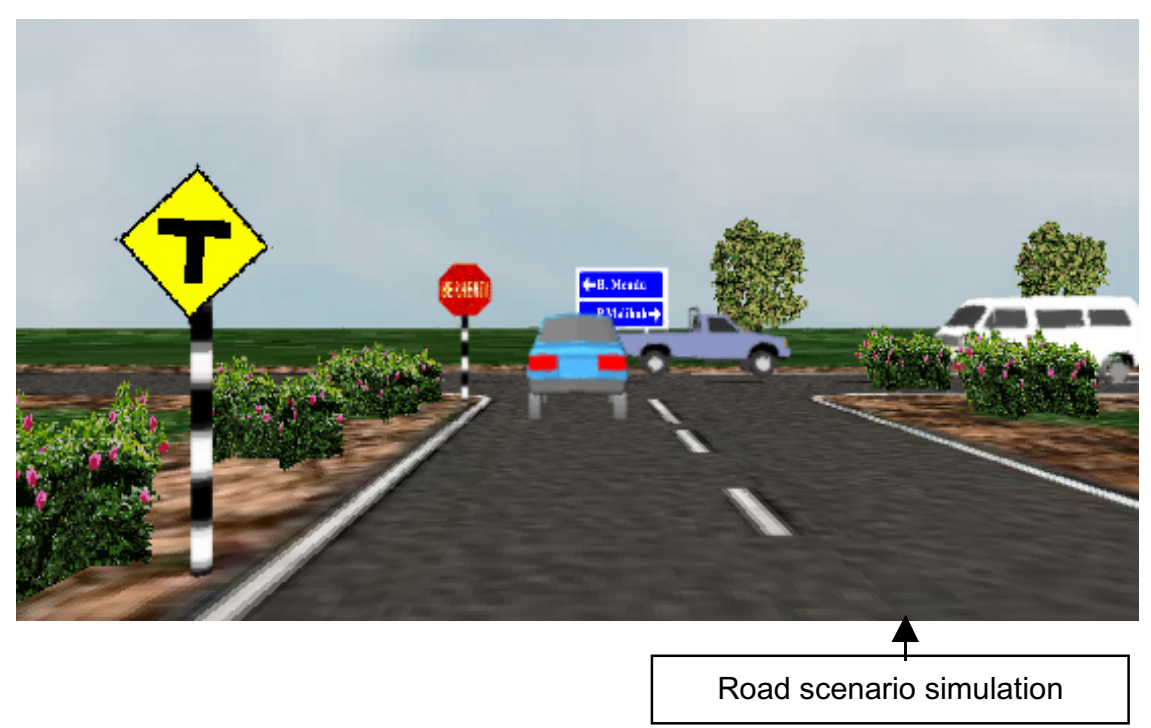

A. Kenderaan biru telah menggunakan lorong yang tidak betul setelah membelok keluar dari persimpangan.

B. Kenderaan biru yang menggunakan lorong kiri jalan sebelum tiba di persimpangan harus juga membelok keluar ke kiri di persimpangan.

C. Kenderaan putih harus memberi laluan kepada kenderaan biru.

D. Tiada kesalahan.

Figure 3: A sample question of the VR based test that is related to traffic rules

Both pre-test and post-test were similar in content but the order of the questions was different to avoid the set response effect. A subject matter expert from the RTD was requested to review the process used to develop the test, as well as the test itself, and then made a judgment about how well these items represent the intended content area. The Cronbach's alpha reliability coefficient was 0.83 , which depicted the test items were satisfactorily reliable. Figure 3 depicts a screenshot of a test item. 
The maximum score for each test was 15. For each question, participants received a score of either 1 (correct answer) or 0 (incorrect answer), and a total score ranging from 0 to 15 . This total score was multiplied by 100 to convert it to a percentage. There were six traffic signs related questions and nine traffic rules related questions.

Bennett, Seashore and Wesman Space Relations Test

This instrument was chosen to test the spatial visualisation ability of the participants. It consists of 60 patterns, which can be folded into figures. A feature inherent in these items is that they required mental manipulation of objects in three dimensional space. It tests the ability to visualise a constructed object from a picture of pattern, which is illustrated in two dimensional. This is consistent with the spatial skill needed to reconstruct the three dimensional view of the road scenario from the two dimensional plan view. This test has a reliability of 0.91 (Bennett, Seashore \& Wesman, 1972). Participants who score $50 \%$ or above are classified as having high spatial visualisation ability and participants who score $50 \%$ or below are classified as having low spatial visualisation ability.

\section{Procedure}

Two weeks before the treatment, the learners were given the Bennett, Seashore and Wesman Space Relations Test and the VR based pre-test. Then, immediately before the treatment, the experimental group was given training on the navigation of the virtual environment. Immediately after the treatment, the learners were given the VR based post-test.

\section{Results}

\section{Distribution of learners}

The 126 learners were divided into two groups. Each group was assigned to one of the two learning modes. A total of 62 learners were assigned to the VR mode while 64 learners were assigned to the Non VR mode.

\section{Testing of Hypothesis 1}

$\mathrm{H}_{1}$ : Learners exposed to the VR mode will have evidence of better learning than those exposed to the Non VR mode.

A one way analysis of covariance (ANCOVA) was conducted to compare the effects of the two modes on learning. This analysis was meant to determine if there was statistically significant difference in the adjusted mean of the dependent variable (gain score) between the two learning modes, while controlling the pre-test. The independent variable was the 
learning mode (VR and Non VR) and the dependent variable was the gain score, which was obtained by subtracting each post-test score from the respective pre-test score. Learners' scores on the pre-test were used as the covariate in the analysis. Preliminary checks were conducted to ensure that there was no violation of the assumptions of normality, linearity, homogeneity of variances, homogeneity of regression slopes, and reliable measurement of the covariate.

Table 1: One way ANCOVA of gain score by learning mode with pre-test score as covariate. Dependent variable: Gain score

\begin{tabular}{|l|c|c|c|c|c|c|}
\hline \multicolumn{1}{|c|}{ Source } & Type III SS & $d f$ & $M S$ & $F$ & Sig. & eta $^{2}$ \\
\hline $\begin{array}{l}\text { Covariate } \\
\text { Pre-test score }\end{array}$ & 12919.724 & 1 & 12919.724 & 67.182 & 0.000 & 0.353 \\
\hline $\begin{array}{l}\text { Main effect } \\
\text { Learning mode }\end{array}$ & 6639.222 & 1 & 6639.222 & 34.524 & 0.000 & 0.219 \\
\hline Error & 23654.133 & 123 & 192.310 & & & \\
\hline Total & 100711.111 & 126 & & & & \\
\hline$p<0.05$
\end{tabular}

After adjusting for the pre-test scores, there was a significant difference between the two learning modes on the gain scores, $F(1,123)=34.524, p=$ 0.000 (see Table 1). The effect size, calculated using eta ${ }^{2}$, was 0.219 , which in Cohen's (1988) terms would be considered a large effect size. Cohen classified 0.01 as a small effect, 0.06 as a medium effect and 0.14 as a large effect. There was also a strong relationship between the pre-test scores and the gain scores, as indicated by the eta ${ }^{2}$ of 0.353 . The VR mode had an adjusted mean, $M$, of 28.751 and the Non VR mode had an adjusted mean, $M$, of 14.231. Thus, it could be concluded that learners exposed to the VR mode obtained significantly higher gain score for the VR based test than learners exposed to the Non VR mode.

\section{Testing of Hypothesis 2}

$\mathrm{H}_{2}$ : Low spatial visualisation ability learners exposed to the VR mode will have evidence of better learning than low spatial visualisation ability learners exposed to the Non VR mode.

A one way ANCOVA was conducted to examine if there was significant difference in adjusted means of the dependent variable (gain score) between the low spatial visualisation ability learners of both learning modes, while controlling the pre-test. After adjusting for the pre-test scores, there was a significant difference between the low spatial visualisation ability learners of the two learning modes on the gain scores, $F(1,57)=13.129, p=0.001$ (see Table 2). This means that the learning mode had a main effect on the low spatial visualisation ability learners' gain scores. The effect size, calculated using eta ${ }^{2}$, was 0.187 , which in Cohen's 
(1988) terms would be considered a large effect size. This effect size indicated that the learning mode effect accounted for $18.7 \%$ of the variance of the low spatial visualisation ability learners' gain scores.

Table 2: One way ANCOVA of gain score by learning mode with pre-test score as covariate for low spatial visualisation ability learners. Dependent variable: Gain score.

\begin{tabular}{|l|c|c|c|c|c|c|}
\hline \multicolumn{1}{|c|}{ Source } & Type III SS & $d f$ & $M S$ & $F$ & Sig. & eta $^{2}$ \\
\hline $\begin{array}{l}\text { Covariate } \\
\text { Pre-test score }\end{array}$ & 7718.155 & 1 & 7718.155 & 32.489 & 0.000 & 0.363 \\
\hline $\begin{array}{l}\text { Main effect } \\
\text { Learning mode }\end{array}$ & 3118.906 & 1 & 3118.906 & 13.129 & 0.001 & 0.187 \\
\hline Error & 13541.105 & 57 & 237.563 & & & \\
\hline Total & 54577.778 & 60 & & & & \\
\hline
\end{tabular}

$p<0.05$

The low spatial visualisation ability learners of the VR mode had higher adjusted mean (adjusted $M=29.894$ ) than the low spatial visualisation ability learners of the Non VR mode (adjusted $M=15.440$ ). Hence, it could be concluded that the low spatial visualisation ability learners exposed to the VR mode obtained significantly higher gain score for the VR based test than the low spatial visualisation ability learners exposed to the Non VR mode.

\section{Testing of Hypothesis 3}

$\mathrm{H}_{3}$ : High spatial visualisation ability learners exposed to the VR mode will have evidence of better learning than high spatial visualisation ability learners exposed to the Non VR mode.

Table 3: One way ANCOVA of gain score by learning mode with pre-test score as covariate for high spatial visualisation ability learners. Dependent variable: Gain score.

\begin{tabular}{|l|c|c|c|c|c|c|}
\hline \multicolumn{1}{|c|}{ Source } & Type III SS & $d f$ & $M S$ & $F$ & Sig. & eta $^{2}$ \\
\hline $\begin{array}{l}\text { Covariate } \\
\text { Pre-test score }\end{array}$ & 5129.109 & 1 & 5129.109 & 32.440 & 0.000 & 0.340 \\
\hline $\begin{array}{l}\text { Main effect } \\
\text { Learning mode }\end{array}$ & 3605.483 & 2 & 3605.483 & 22.803 & 0.000 & 0.266 \\
\hline Error & 9961.087 & 63 & 158.112 & & & \\
\hline Total & 46133.333 & 66 & & & & \\
\hline$p<0$
\end{tabular}

$p<0.05$

A one way ANCOVA was conducted to examine if there was a significant difference in adjusted mean of the dependent variable (gain score) between the high spatial visualisation ability learners of the two learning modes, while controlling the pre-test. After adjusting for the pre-test scores, there 
was a significant difference between the high spatial visualisation ability learners of the two learning modes on the gain scores, $F(1,63)=22.803, p=$ 0.000 (see Table 3 ). This means that the learning mode had a main effect on the high spatial visualisation ability learners' gain scores. The effect size, calculated using eta ${ }^{2}$, was 0.266, which in Cohen's (1988) terms would be considered a large effect size. This effect size indicated that the learning mode effect accounted for $26.6 \%$ of the variance of the high spatial visualisation ability learners' gain scores.

The high spatial visualisation ability learners of the VR mode had a higher adjusted mean (adjusted $M=27.832$ ) than the high spatial visualisation ability learners of the Non VR mode (adjusted $M=13.021$ ). Hence, it could be concluded that the high spatial visualisation ability learners exposed to the VR mode obtained significantly higher gain scores for the VR based test than the high spatial visualisation ability learners exposed to the Non VR mode.

\section{Testing of Hypothesis 4}

$\mathrm{H}_{4}$ : In the VR mode, high spatial visualisation ability learners will have evidence of better learning than low spatial visualisation ability learners.

Table 4: ANCOVA of gain score by spatial visualisation ability with pretest score as covariate for VR mode. Dependent variable: Gain score

\begin{tabular}{|l|c|c|c|c|c|c|}
\hline \multicolumn{1}{|c|}{ Source } & Type III SS & df & MS & $\boldsymbol{F}$ & Sig. & eta $^{2}$ \\
\hline $\begin{array}{l}\text { Covariate } \\
\text { Pre-test score }\end{array}$ & 6054.738 & 1 & 6054.738 & 23.589 & 0.000 & 0.286 \\
\hline $\begin{array}{l}\text { Main effect } \\
\text { Spatial visualisation ability }\end{array}$ & $\mathbf{4 7 . 1 7 6}$ & $\mathbf{1}$ & $\mathbf{4 7 . 1 7 6}$ & $\mathbf{0 . 1 8 4}$ & $\mathbf{0 . 6 7 0}$ & $\mathbf{0 . 0 0 3}$ \\
\hline Error & 15143.781 & 59 & 256.674 & & & \\
\hline Total & 72311.111 & 62 & & & & \\
\hline
\end{tabular}

$p<0.05$

A one way ANCOVA was conducted to examine if there was significant difference in adjusted mean of the dependent variable (gain score) between low spatial visualisation ability learners and high spatial visualisation ability learners, while controlling the pre-test. Learners' scores on the pretest were used as the covariate in the analysis. After adjusting for the pretest scores, it was found that there was no significant difference in the adjusted mean gain scores for the high and low spatial visualisation ability learners of the VR mode, $F(1,59)=0.184, p=0.670$ (see Table 4 ).

The adjusted mean for the high spatial visualisation ability learners was 29.561 and the adjusted mean for the low spatial visualisation ability 
learners was 27.801. The adjusted mean difference of 1.76 was not significant. Thus, it could be concluded that the adjusted mean for the gain score between the high spatial visualisation ability VR mode learners and the low spatial visualisation ability learners of the same mode did not differ significantly.

\section{Testing of Hypothesis 5}

$\mathrm{H}_{5}$ : There is an interaction effect between the learners' spatial visualisation ability and the learning mode, related to gain score of the VR based test.

A 2 by 2 two way ANCOVA was conducted to examine the effects of the learning modes on the performance in the VR based test for low spatial visualisation ability learners and high spatial visualisation ability learners. The independent variables were the learning mode (VR and Non VR) and spatial visualisation ability (low and high). The dependent variable was the gain score of the VR based test and learners' scores on the VR based pretest were used as the covariate in the analysis.

Table 5: Two way ANCOVA of gain score by learning mode and spatial visualisation ability with pre-test score as covariate. Dependent variable: Gain score

\begin{tabular}{|c|c|c|c|c|c|c|}
\hline Source & Type III SS & $d f$ & MS & $F$ & Sig. & eta $^{2}$ \\
\hline $\begin{array}{l}\text { Covariate } \\
\text { Pre-test score }\end{array}$ & 12770.023 & 1 & 12770.023 & 65.531 & 0.000 & 0.351 \\
\hline $\begin{array}{l}\text { Main effects } \\
\text { Learning mode (LM) } \\
\text { Spatial visualisation ability } \\
\text { (SVA) }\end{array}$ & $\begin{array}{c}6636.703 \\
73.624\end{array}$ & $\begin{array}{l}1 \\
1\end{array}$ & $\begin{array}{l}6636.703 \\
73.624\end{array}$ & $\begin{array}{c}34.057 \\
0.378\end{array}$ & $\begin{array}{l}0.000 \\
0.540\end{array}$ & $\begin{array}{l}0.220 \\
0.003\end{array}$ \\
\hline $\begin{array}{l}2 \text { way interaction } \\
\text { LM SVA }\end{array}$ & 1.125 & 1 & 1.125 & 0.006 & 0.940 & 0.000 \\
\hline Error & 23579.433 & 121 & 194.871 & & & \\
\hline Total & 100711.111 & 126 & & & & \\
\hline
\end{tabular}

$p<0.05$

The two way ANCOVA results, as shown in Table 5, indicated that the interaction between learning mode and spatial visualisation ability was not significant, $F(1,121)=0.006, p<0.940$. This means the differences in the adjusted means of the gain score between the two learning modes did not vary as a function of learners' spatial visualisation abilities. Although the effect of the learning modes on the gain scores of the VR based test did not depend on the spatial visualisation ability level, there were differences in gain scores among the learning modes for learners of different spatial visualisation abilities. The VR mode had higher gain score than the Non VR mode for both the low and high spatial visualisation ability learners. 
The results in Table 5 also show that the main effect due to spatial visualisation ability was not statistically significant, $F(1,121)=0.378, p<$ 0.540 . The adjusted mean of the gain score for the high spatial visualisation ability learners, averaged across the two learning modes, 22.234, was not significantly higher than the adjusted mean of the gain score for the low spatial visualisation ability learners, 20.677. Table 6 presents the means, standard deviations, adjusted means, and standard error of the gain score by learning mode and spatial visualisation ability.

Table 6: Means, standard deviations, adjusted means, and standard errors of gain score by learning mode and spatial visualisation ability

\begin{tabular}{|l|c|c|c|c|c|}
\hline \multirow{2}{*}{$\begin{array}{c}\text { Learning } \\
\text { mode }\end{array}$} & $\begin{array}{c}\text { Spatial visualisation } \\
\text { ability }\end{array}$ & \multicolumn{4}{|c|}{ Gain score } \\
\cline { 3 - 6 } & Low $(\mathrm{N}=30)$ & 29.1111 & 21.6898 & $27.850^{\mathrm{a}}$ & 2.553 \\
\hline \multirow{2}{*}{ VR } & High $(\mathrm{N}=32)$ & 28.3333 & 15.6118 & $29.597^{\mathrm{a}}$ & 2.473 \\
\hline Non VR & Low $(\mathrm{N}=30)$ & 16.2222 & 16.2059 & $13.504^{\mathrm{a}}$ & 2.571 \\
\cline { 2 - 6 } & High $(\mathrm{N}=34)$ & 12.5490 & 15.1103 & $14.872^{\mathrm{a}}$ & 2.411 \\
\hline
\end{tabular}

Note: ${ }^{\text {a }}$ Evaluated at covariate appeared in the model: pre-test $=57.6720$

Thus, the statistical results depicted that there was no significant interaction between the learning modes and the learners' spatial visualisation abilities. This means the effect of the learning modes on the gain scores of the VR based test did not depend on the spatial visualisation ability levels. The main effect due to spatial visualisation ability was also not statistically significant.

\section{Discussion}

\section{VR mode versus Non VR mode}

Learners exposed to the VR mode significantly outperformed the learners exposed to the Non VR mode. The cognitive theory of multimedia learning (Mayer, 2002), with its underlying cognitive load theory (Sweller, 1999) and dual coding theory (Paivio, 1986), help to explain this finding. This is elaborated below.

A possible explanation for this finding is related to the prediction that overloading the working memory results in less effective learning. Most spatial problems require learners to deal with the construction of three dimensional mental representations (Carpenter \& Just, 1986; Cooper, 1988; Keenan \& Moore, 1979) in order to understand and manipulate given spatial information. The content and structure of mental representation of spatial information, and how easily and accurately it is constructed and maintained during processing, is central to dealing successfully with spatial problems (Carpenter \& Just, 1986). According to Pillay (1997; 1998), 
the construction and understanding of three dimensional representations involves complex cognitive activities, such as integrating information from various sources, constructing meaning from abstruse elements in the graphical information, constructing hidden or obscured information, constructing and maintaining three dimensional representations of the components and of the complete object, retrieving relevant schemas, encoding or constructing information from given spatial representations, and finally, performing transformations on these representations.

The learning problem that was chosen in this project is an example of a spatial problem. Learners of the VR mode outperformed the learners of the Non VR mode because in addition to text and image materials, learners of the VR mode were also provided with virtual environments. The use of virtual environments providing three dimensional representations that mimic various real world road scenarios, offer virtual experience of navigating through them, and show the movement of vehicles in the VR mode, primarily eliminate the learners' need to mentally construct and maintain the three dimensional representation and dynamics of the road scenario. On the contrary, learners in the Non VR mode need to involve more complex cognitive activities. These include integrating information from text and two dimensional plan views regarding the road scenarios, constructing meaning of abstruse elements in the graphical and text information, particularly on the dynamics of the virtual vehicles, constructing the depth information of the road scenario, which is unavailable when presented using two dimensional plan views, constructing and maintaining the three dimensional representation and dynamics of the road scenarios, retrieving relevant schema to support these cognitive activities, and encoding information from the formed spatial representations.

Sweller (1999) argues that the cognitive load imposed by task information may exhaust the cognitive resources of individuals and consequently affect learning. In the Non VR mode, learners are required to involve complex cognitive activities by directing attention to multiple sources of information, and to synthesise these before proceeding any further. The need to integrate information from multiple sources imposes extraneous cognitive load that may inhibit learning (Chandler \& Sweller, 1992). Sweller (1999) also argues that for learning to occur, learners must attend to essential concepts associated with the task and must develop schemas. Attention must be directed to learning the essential concepts and not to extraneous processes. Many of the cognitive activities that occur in the Non VR mode as mentioned earlier are presumably imposing extraneous demands on limited cognitive resources, Indeed, many of these activities are not essential for learning the content, but become necessary due to the instructional format. As the cognitive capacity is limited, the use of 
cognitive resources for extraneous cognitive demands may cause insufficient resources available for learning (Sweller, 1999). On the other hand, the incorporation of virtual environments into the VR mode provides a more automated spatial encoding and therefore does not require specific spatial processing schema to mentally construct a three dimensional view from the respective two dimensional plan view, which occurs in the Non VR mode. Based on the cognitive load theory (Sweller, 1999), the amount of mental resources that deal with extraneous cognitive load can be reduced with the availability of such support, thus leaving more resources for intrinsic cognitive load. This most probably explains the significant positive effects of the VR mode when compared with the Non VR mode.

Learners of the Non VR mode were exposed to materials in the form of text and two dimensional image, but were tested on the VR based test, which posed questions that showed three dimensional simulation of virtual road scenarios. The dissimilarity in the representations between the learning environment and the test poses the need for the Non VR learners to use another level of abstraction when answering the VR based test. Based on the cognitive load theory (Sweller, 1999), this once again imposes a higher level of extraneous cognitive load on the Non VR learners, particularly for those who do not have the necessary schema for spatial processing in the long term memory. As a result, learners in this mode performed less well than their VR counterparts, in the VR based test. The following provides several possible explanations based on dual processing.

Paivio $(1971,1986)$ was among the first to demonstrate experimentally that spatial processing (in the form of mental imagery) can enhance the recall of verbal information. Numerous studies show that the processing of adjunct spatial information can enhance the comprehension and recall of the text material (e.g. Alesandrini, 1984; Dean \& Kulhavy, 1981; Rieber, 1994; Schwartz \& Kulhavy, 1981). Adjunct verbal processing is also shown to enhance spatial learning (Kulhavy, Lee, \& Caterino, 1985; Schofield \& Kirby, 1994). These enhancement or collaborative effects are interpreted in terms of dual coding (Paivio, 1971, 1986).

The VR mode utilises mostly text, images, and virtual environments, which also implies that this learning mode involves both verbal (text) and nonverbal (images and virtual environments) processing. Based on the dual coding theory, both verbal and non-verbal processing have equal weight and as stated in Kirby (1993), the activation of this dual processing has three advantages: (a) it results in a more elaborate encoding of the material to be learned, providing increased retrieval cues; (b) more information can be stored by dual coding, because verbal and spatial information are stored separately, and (c) the alternative store may be optimal for retaining certain types of information. These advantages are termed as enhancement or 
collaborative effects and probably explain the significant positive effects of the VR mode.

Despite the numerous studies that demonstrate the enhancement effects, examples are found of tasks in which verbal and spatial processing compete rather than collaborate (e.g., Kirby, Jurisich \& Moore, 1984; Kirby, 1990). In such cases, dual processing does not enhance learning and is known to produce competitive effects. The Non VR mode primarily comprises text and images (2D plan views). As with the VR mode, Non VR mode also involves both verbal (text) and non-verbal (images) processing or both auditory and visual processing as defined in the cognitive theory of multimedia learning. Nevertheless, this study found that the dual coding or processing that occurred in the Non VR mode did not assist learning as much as the dual processing that occurred in the VR mode.

Kirby (1993) identifies four boundary conditions when dual coding is likely to result in collaborative or competitive effects: task interference, focus of attention, nature of the information, and individual differences. In the case of VR mode versus Non VR mode, the conditions on task interference and nature of the information are found particularly relevant to explain the finding reported earlier.

Dual processing requires two tasks to be performed simultaneously. However, according to Kirby (1993), if the required verbal encoding and non-verbal encoding are not automated, they will compete for the limited cognitive resources. The greater the difficulty in performing each of the tasks, the greater the interference will be, which will then lead to greater competitive effects. The absence of virtual environments in the Non VR mode that provide three dimensional representation, offer virtual navigation experience and show the dynamics of the road scenarios, or the reliance on two dimensional plan views that require learners to use complex cognitive activities to construct and comprehend the three dimensional representations produces a less automated spatial encoding. As described in Kirby (1993), this potentially increases the cognitive load, causes more difficulty in performing the spatial task and leads to greater interference with the verbal task. On the hand, the VR mode produces less cognitive load. This causes less interference between the verbal task and the non-verbal task, which also infers collaboration instead of competition between the two tasks.

Another boundary condition of dual coding that can explain this finding is the 'nature of the information'. Kirby (1993) points out that not all information is equally amenable to both non-verbal and verbal coding. Abstract verbal propositions are not easily coded non-verbally (e.g. spatially), at least without loss of crucial information. Conversely, much 
non-verbal (e.g. spatial) information is difficult to code verbally. Too much effort in encoding information will distract learners from other content and/or cause interference. This learning problem, which is meant to help learners to interpret various traffic rules, is spatial in nature. Thus, the use of virtual environments to present spatial information in the VR mode, which mimics the real world representation requires less encoding effort and therefore assists more in the learning than the Non VR mode. On the other hand, in the Non VR mode, much effort in encoding verbal (text) and non-verbal (image instead of spatial) for information that is spatial in nature, results in competitive effects.

Nevertheless, the significant positive effects of the VR mode may also be due to the fact that learners in the VR mode learned traffic rules using the VR based learning environment, and then were tested with items that involved the same modality. As the VR simulations of various road incidents in the test items portrayed much the same scenes as those used in the learning session, the significant positive results of those in the VR mode may thus reflect the benefits of this repetition rather than the learning of traffic rules per se.

\section{Effects of the learning mode on learning based on spatial visualisation ability levels}

The findings that both high and low spatial visualisation ability learners benefit from the VR mode, and that the difference between the performances of these two groups of learners is not significant, is inconsistent with the studies by Mayer and Sims (1994) and Toh (1998). These studies provide preliminary evidence that high spatial ability learners benefit more from improved instructional design than do low spatial ability learners. There are several possible explanations for this finding.

First, the use of virtual environments that explicitly present the three dimensional representations and dynamics of the road scenarios, and the use of additional navigational aids to help learners to stay oriented in the VR mode, have greatly reduced the learners' need to use their existing spatial processing schema. This reduces the extraneous cognitive load, which subsequently enables the high spatial visualisation ability learners to spare most of their cognitive resources for comprehending the content of the learning environment. This possibly has explained the significant positive effect of this learning mode on the high spatial visualisation ability learners.

Second, in this learning mode, the lack of spatial processing schema among the low spatial visualisation ability learners also has not negatively affected 
the learning by this group. The explicit presentation of three dimensional representation and dynamics of the road scenarios and the use of additional navigational aids have kept the need for using this schema to a minimum. Thus, the low spatial visualisation ability learners of the VR mode significantly outperform their Non VR counterparts, as they are able to use their cognitive resources for comprehending the content, rather than using these resources to support the additional cognitive activities that are necessary in the effort to comprehend the content, such as those occurring in the Non VR mode.

The finding that the low spatial visualisation ability learners of the VR mode significantly outperform their Non VR counterparts may also be explained by Messick's strategies for matching individual differences and learning task. Messick (1976) proposed three strategies: the challenge match, the capitalisation match, and the compensatory match. The challenge match uses a deliberate mismatch between task demands and learner capabilities, to force a learner to change and become more flexible. The capitalisation match aims to tailor task demands to match the learners' strengths, and the compensatory match aims to offset learners' deficiencies by providing cognitive tools that learners cannot readily provide for themselves.

The VR mode that produces significant positive effects for both high and low spatial visualisation ability learners employs the compensatory matching technique. The use of virtual environments, which are unavailable in the Non VR mode, compensates for the need to mentally construct and maintain the three dimensional representation and dynamics of the road scenarios. The non-significant difference between high spatial visualisation ability learners and low spatial visualisation ability learners of the VR mode proves the success of the compensatory match. Stanney and Salvendy (1995), in their study, also reveal that the performance gap between high spatial individuals and low spatial individuals disappears with the use of interface design that can avoid the need for mentally structuring embedded information. This interface improves the performance of low spatial ability learners due to the compensatory match of their abilities.

Interaction effects

Another finding from this study is that the interaction effect between the learners' spatial visualisation abilities and the two learning modes is not significant. This implies that the effects of the learning modes on learning do not depend on the learners' differences in terms of spatial visualisation ability. However, between the two learning modes, VR mode provides more positive effect to both low spatial visualisation ability learners and high spatial visualisation ability learners. Indeed, both low spatial 
visualisation ability learners and high spatial visualisation ability learners benefit equally from this learning mode. This implies that the learners benefit from the VR mode, irrespective of their spatial visualisation abilities.

\section{Implications of the project}

There are four major implications of this project as elaborated below.

\section{Feasible instructional design theoretical framework}

Figure 1 illustrates the overall instructional design theoretical framework that guided the design of the VR based learning environment. This framework could serve as a feasible and useful template to guide the design of other VR based learning environments, particularly learning environments that adopt the new paradigm of instruction (constructivist based). The fact that a robust model for guiding the design of learning environment using this technology is still unavailable at present, this framework functions as an initial structure which can be further refined and/or revised in the effort to generate a robust design model for such learning environment.

\section{Feasible constructivist instructional development model}

Virtual environment technology is noted as capable of affording constructive learning (Bricken, 1990; Chen \& Teh, 2000; Greening, 1998; Jonassen et al., 2000; Winn, 1993), and a comprehensive review of educational uses of virtual environment technology by Youngblut (1998) reveals that applications that explicitly embody some form of pedagogy all support constructivist learning. Although many of these applications make known the employed philosophy of pedagogy, very few of them report on the adopted instructional development models. In this regard, the successful development of the learning environment in this project provides evidence on the feasibility to employ a constructivist instructional model (R2D2 model) to guide the design and development process of VR based learning environments. Such model can also be used to guide the design and development process of other VR based learning environments and will be particularly appropriate for learning environments that employ the constructivist paradigm.

\section{VR based learning environment - an effective alternative}

The significant positive effects of the VR based learning environment (referring to the VR mode) on learning when compared with the Non VR 
mode provides another evidence of the potentials of VR technology for instructional use. This VR based learning environment provides new learning opportunities by introducing learning activities that make visible concepts and relationships that are not easily grasped or visualized by learners when relying only on the conventional method. The feasibility of implementing this VR based learning environment in terms of technical, economic, and social, and the proven effectiveness of this method over the conventional method provide strong justifications to suggest the RTD of Malaysia to consider incorporating this novel learning method into the current novice car driver instruction programme.

\section{ATI study}

The vast majority of the research into virtual environments for instructional use is technology driven, rather than taking into account the human factor. There has been little study on how learner characteristics interact with the features of virtual environments either to aid or inhibit learning. The ATI study that was conducted provides more understanding of this aspect. The findings of this study show that learners benefit most from the VR mode, irrespective of their spatial visualisation abilities. This proves the VR based learning environment offers a promising medium to accommodate individual differences in terms of this aptitude.

\section{Recommendations and conclusion}

This project raises a couple of other interesting issues that worth further investigations. First, in the effort to further refine and/or revise the design and development framework (both instructional design theoretical framework and instructional development model) more design and development of various types of VR applications based on the proposed framework are needed. This will lead to the generation of a more robust and comprehensive design and development framework for VR based learning environments. Second, the interaction effects of VR based learning environment can be extended to other differences among the learners, such as locus of control, types of personality, field dependency, gender, motion sickness history, and computer literacy. This will further enlighten us on how learner characteristics interact with the features of virtual environments to either aid or inhibit learning.

As a conclusion, this project proposes a feasible instructional design theoretical framework that can be used to guide the design of other VR based learning environments. This framework provides an initial structure that can be further refined and/or revised in the effort to generate a robust design model for such learning environment. The successful development 
of the VR based learning environment also proves the feasibility and appropriateness to employ a constructivist instructional development model (R2D2 model) to guide the design and development process of VR based learning environments. The fact that real learning problem related to the novice car driver instruction programme has been chosen in this project and the significant positive effects of the VR mode over the Non VR mode, which is employed in the current instruction programme, provides a strong justification to the RTD that VR based learning environment makes an effective alternative to the current method. The ATI study also shows the benefit of the VR based learning environment in accommodating individual differences in terms of spatial visualisation ability. In short, the outcomes of this work provide another confirmation on the high potential of VR technology for instructional use. It also points to the worthiness to further investigate the methods that can improve the effectiveness of VR based learning environments.

\section{References}

Alesandrini, K.L. (1984). Pictures and adult learning. Instructional Science, 13, 63-77.

Alessi, S.M. \& Trollip, S.R. (2001). Multimedia for learning: Methods and development. Massachusetts: Allyn \& Bacon.

Bennett, G.K., Seashore, H.G. \& Wesman, A.G. (1972). Manual of differential aptitude test. New York: The Psychological Corporation.

Bricken, W. (1990). Learning in virtual reality. (Tech. Memo. M-90-5). Seattle, WA: Human Interface Technology Laboratory, University of Washington.

Carpenter, P.A. \& Just, M.A. (1986). Spatial ability: An information processing approach to psychometric. In R.J. Sternberg (Ed), Advances in the Psychology of Human Intelligence, 3 (pp. 221-253). Hillsdale, NJ: LEA.

Chandler, P. \& Sweller, J. (1992). Split attention effects as a factor in the design of instruction. British Journal of Educational Psychology, 62, 233-246.

Chen, C.J. \& Teh, C.S. (2000). An affordable virtual reality technology for constructivist learning environments. The 4 th Global Chinese Conference on Computers in Education (pp. 414-421). Singapore.

Chen, C.J., Toh, S.C. \& Wan, M.F. (2003). Virtual reality: A potential technology for providing novel perspective to novice driver education in Malaysia. In N. Ansari et al. (Eds), Proceedings of the International Conference on Information Technology: Research and Education (pp. 184-188). New Jersey: IEEE.

Chen, C.J., Toh, S.C. \& Wan, M.F. (2004). The theoretical framework for designing desktop virtual reality-based learning environments. Journal of Interactive Learning Research., 15(2), 147-167. 
Chen, C.J. \& Toh, S.C. (2005). A feasible instructional development model for virtual reality (VR)-based learning environments: Its efficacy in the novice car driver instruction of Malaysia. Educational Technology Research E Development, 53(1), 111-123.

Cohen, J. (1988). Statistical power analysis for the behavioral sciences. Hillsdale, NJ: Erlbaum.

Computer-based traffic rules and regulations test: More than 200,000 failures (in Chinese). (28 November 2003). Sin Chew Jit Poh. [viewed 28 Nov 2003]. http://www.sinchewi.com/print.phtml?sec=1 \&artid=200311280278

Cooper, L.A. (1988). The role of spatial representations in complex problem solving. In S. Schiffer \& S. Steele (Eds), Cognition and Representation (pp. 53-86). Boulder, CO: Westview.

Dean, R.S. \& Kulhavy, R.W. (1981). Influence of spatial organization in prose learning. Journal of Educational Psychology, 73, 57-64.

Gagné, R.M. \& Merrill, M.D. (1990). Integrative goals for instructional design. Educational Technology Research \& Development, 38(1), 23-30.

Greening, T. (1998). Building the constructivist toolbox: An exploration of cognitive technologies. Educational Technology, 38(2), 28-35.

Gustafson, K.L. (2002). The future of instructional design. In R.A. Rieser \& J.V. Dempsey (Eds), Trends and issues in instructional design and technology. New Jersey: Merrill Prentice Hall.

Jonassen, D.H. (1999). Designing constructivist learning environments. In C.M. Reigeluth (Ed), Instructional-design theories and models: A new paradigm of instructional theory (Vol. 2, pp. 215-239). New Jersey: Lawrence Erlbaum.

Jonassen, D.H., Hernandez-Serrano, J. \& Choi, I. (2000). Integrating constructivism and learning technologies. In M. Spector \& T.M. Anderson (Eds), Integrated and holistic perspectives on learning, instruction and technology: Understanding complexity (pp.103-127). Netherlands: Kluwer Academic.

Keenan, J.M. \& Moore, R.E. (1979). Memory for images of concealed objects: A reexamination of Neisser and Kerr. Journal of Experimental Psychology: Human Memory and Learning, 5, 374-385.

Kirby, J.R. (1990). Spatial cognition in education. International Congress of Applied Psychology, Kyoto, Japan.

Kirby, J.R. (1993). Collaborative and competitive effects of verbal and spatial processes. Learning and Instruction, 3, 201-214.

Kirby, J.R., Jurisich, R. \& Moore, P.J. (1984). Effects of map processing upon text comprehension. Annual meeting of the American Psychological Association, Toronto, Canada. 
Kozma, R.B. (1994). Will media influence learning? Reframing the debate. Educational Technology Research \& Development, 42(2), 7-19.

Kulhavy, R.W., Lee, J.B., \& Caterino, L.C. (1985). Conjoint retention of maps and related discourse. Contemporary Educational Psychology, 13, 169-184.

Mayer, R.E. (2002). Multimedia learning. Cambridge: Cambridge University Press.

Mayer, R.E. \& Sims, V.K. (1994). For whom is a picture worth a thousand words? Extensions of a dual-coding theory of multimedia learning. Journal of Educational Psychology, 86, 389-401.

McGee, M.G. (1979). Human spatial abilities, sources of sex differences. New York: Praeger.

Messick, S. (1976). Individuality in learning. San Francisco: Jossey-Bass.

Paivio, A. (1971). Imagery and verbal processes. New York: Holt, Rinehart \& Winston.

Paivio, A. (1986). Mental representations. New York: Oxford University Press.

Pillay, H.K. (1997). Cognitive load and assembly tasks: Effects of instructional formats on learning assembly procedures. Educational Psychology, 17(3), 285-299.

Pillay, H.K. (1998). Cognitive process and strategies employed by children to learn spatial representations. Learning and Instruction, 8(1), 1-18.

Reeves, T.C. (2000). Enhancing the worth of instructional technology research through "design experiments" and other development research strategies. Paper presented at International Perspectives on Instructional Technology Research for the 21st Century. New Orleans, LA, USA. [verified 1 Mar 2006] http://it.coe.uga.edu/ treeves/AERA2000Reeves.pdf

Reigeluth, C.M. \& Frick, T.W. (1999). Formative research: A methodology for creating and improving design theories. In C.M. Reigeluth (Ed), Instructionaldesign theories and models: A new paradigm of instructional theory (pp. 633-652). New Jersey: Lawrence Erlbaum.

Reigeluth, C.M. (1999). What is instructional-design theory and how is it changing?. In C.M. Reigeluth (Ed), Instructional-design theories and models: A new paradigm of instructional theory (pp. 5-29). New Jersey: Lawrence Erlbaum.

Reigeluth, C.M. \& Merrill, M.D. (1978). A knowledge base for improving our methods of instruction. Educational Psychologist, 13, 54-70.

Rieber, L. (1994). Computers, graphics, and learning. Madison: WCB Brown \& Benchmark.

Rieber, L. (1996). Seriously considering play: Designing interactive learning environments based on the blending of microworlds, simulations, and games. Educational Technology Research \& Development, 44(2), 43-58. 
Roblyer, M.D. \& Knezek, G. (2003). New millenium research for educational technology: A call for a national research agenda. Journal of Research on Technology in Education, 36(1), 60-71.

Schofield, N. J. \& Kirby, J. R. (1994). Position location on a topographical map: Effects of abilities, preferences, and instruction. Cognition and Instruction, 12, 3560.

Schwartz, N.H. \& Kulhavy, R.W. (1981). Map features and the recall of discourse. Contemporary Educational Psychology, 6, 151-158.

Sweller, J. (1999). Instructional design in technical areas. Camberwell, Australia: ACER.

Stanney, K.M. \& Salvendry, G. (1995). Information visualisation: Assisting low spatial individuals with information access tasks through the use of visual mediators. Ergonomics, 38(6), 1184-1198.

Toh, S.C. (1998). Cognitive and motivational effects of two multimedia simulation presentation modes on science learning. (Unpublished doctoral thesis). Centre for Instructional Technology and Multimedia, University Science Malaysia.

Wilson, B.G. (1997). The postmodern paradigm. In R.D. Charles \& A.J. Romiszowski (Eds), Instructional development paradigms (pp. 297-309). New Jersey: Educational Technology Publications.

Willis, J. (2000). The maturing of constructivist instructional design: Some basic principles that can guide practice. Educational Technology, 40(1), 5-16.

Willis, J. \& Wright, K. (2000). A general set of procedures for constructivist instructional design: The new R2D2 model. Educational Technology, 40(2), 5-20.

Winn, W.D. (1993). A conceptual basis for educational applications of virtual reality. Human Interface Technology Laboratory. (Tech. Rep. R-93-9). Seattle, WA: Human Interface Technology Laboratory.

Youngblut, C. (1998). Educational uses of virtual reality technology. (Tech. Rep. IDA Document D-2129). Alexandria, VA: Institute. [verified 1 Mar 2006] http:/ / www.hitl.washington.edu/scivw/youngblut-edvr/D2128.pdf

Dr Chwen Jen Chen, Faculty of Cognitive Sciences and Human Development, Universiti Malaysia Sarawak. http://www.unimas.my/ Email: cjchen_usm@yahoo.com 